\title{
DESAPRENDIZAJE E INESTABILIDAD. PERSPECTIVAS PARA UNA TEORÍA COGNITIVA DE LA LECTURA POÉTICA
}

\author{
UNLEARNING AND INSTABILITY. \\ PERSPECTIVES FOR A COGNITIVE THEORY OF POETIC \\ READING
}

\author{
Amelia GAMONEDA LANZA \\ Universidad de Salamanca \\ gamoneda@usal.es
}

Resumen: La lectura poética explora técnicas que rescatan procesos cognitivos básicos y aún no automatizados que todo aprendizaje lector activa. Asimismo, la lectura poética sostiene e incentiva los estados de inestabilidad cognitiva por los que ha de pasar cualquier proceso mental. Se configuran así estrategias cognitivas de desaprendizaje de automatismos y de irresolución de interpretaciones que tienen como resultado el extrañamiento y la complejidad, y que se analizarán en el contexto de un poema de Baudelaire.

Palabras clave: Lectura poética. Cognición y lectura. Extrañamiento. Desaprendizaje. Baudelaire.

Abstract: This poetic reading explores techniques which rediscover basic cognitive processes which up to now have not been automated and 
which all readers draw upon. At the same time, the poetic reading sustains and incentivizes the state of cognitive instability through which every mental process passes. In this way the article shows cognitive strategies of unlearning of methods already learned and strategies of maintaining irreconcilable interpretations which result in estrangement and complexity, and which will be analyzed in the context of a poem by Baudelaire.

Key Words: Poetic reading. Cognition and reading. Estrangement. Unlearning. Baudelaire

La lectio (que es la enunciación del libro) [...] suscita un significado que no preexiste en el "texto" o en la página imaginaria. Es una tensión entre un objeto del que un cuerpo se ha sustraído y un objeto al que un cuerpo viene a añadir su existencia, la singularidad de su deseo, los medios de su pensamiento y los sedimentos de su memoria. Quignard, "Lectio", Pequeños tratados II (2016b)

\section{DE LA INESTABILIDAD COGNITIVO-POÉTICA}

Dice la máxima con intención exhortativa que "leer es vivir dos veces", y cree estar hablando de modo metafórico. Pero lo cierto es que hay en ella buena parte de verdad literal, pues leer proporciona experiencias semejantes a las que se obtienen mediante inmersión en el mundo real (quien imagina una escena enciende sus neuronas de un modo similar a quien la vive) y, además de la experiencia emocional, intelectual, estésica 
y estética, se produce en nuestro cerebro un muy real entrenamiento cognitivo que deja huellas comprobables tanto en su fisiología como en su funcionamiento.

Cualquier actividad humana amplía la cantidad y la cualidad de lo conocido al tiempo que hace más potente el instrumento de conocimiento, pero el sorprendente invento de la lectura — no previsto por la biología-, su vinculación con el lenguaje - que en su grado de complejidad es aptitud exclusivamente humana - y la larga historia de su práctica hacen de ella un verdadero laboratorio para los procesos de nuestro cerebro. La subespecie de esta práctica que llamamos "lectura poética" los pone aún más de relieve, pues tal lectura no designa tanto el acto lector de un poema como el modo lector en el que el propio proceso de lectura se muestra a sí mismo en su hacerse. La lectura poética es una lectura en construcción.

El interés neurobiológico que despierta la posibilidad de contemplar este proceso lector ha dado lugar a encuentros interdisciplinares que reciben el nombre de "poética cognitiva" o de "neurohermenéutica", y cada vez son más los equipos mixtos que trabajan en esa coyuntura que a ambas culturas — ciencias y humanidades - interesa ${ }^{1}$. Desde la perspectiva literaria, este acercamiento no debería ser excesivamente sorprendente, ya que la literatura ha sido desde siempre investigación práctica sobre los modos que el lenguaje tiene de conceptualizar, estructurar, articular e innovar pensamiento, y sobre la vinculación de estos modos tanto con nuestra condición corpórea dotada de aparato sensomotor como con las estructuras guardadas en nuestra memoria y en nuestra experiencia (y mediadas por la cultura).

Bien se sabe que leer no es una función natural —al modo en que lo son nuestras capacidades perceptivas - y que durante mucho tiempo la especie humana fue iletrada. La lectura utiliza procesos neuronales en

\footnotetext{
${ }^{1}$ En España el grupo ILICIA trata de aproximarse a estas perspectivas. El presente artículo se ha realizado en el seno del Proyecto de Investigación Inscripciones literarias de la ciencia: cognición, epistemología y epistemocrítica (ILICIA), subvencionado por el MINECO. Ref. FFI2017-83932-P.
} 
origen dedicados a otras funciones: según Dehaene, el reconocimiento visual de las letras reutiliza zonas destinadas al reconocimiento de objetos (también rostros y formas geométricas) como invariables a pesar de ser percibidos desde otro ángulo o en movimiento. Los valores estéticos de un lenguaje que se capta mediante la lectura (esto es, la literatura) se derivan pues de procesos dedicados a otras funciones. Y los conceptos de armonía y disonancia pertenecientes a la estética y compartidos por artes diversas podrían entonces, en la lectura, ser analizados en relación con funciones como la del reconocimiento de la invariabilidad/variabilidad de los objetos. Esta vinculación del análisis estético al análisis estésico no parece aún analizable en términos neurológicos, pero sí que permite aproximaciones cognitivas y de teoría estética. Y, en lo que se refiere a la lectura literaria y específicamente poética (que es la que aquí nos ocupará), la intención de estas páginas es precisamente implicar la capacidad perceptiva humana $-\mathrm{y}$ más generalmente sensomotora - en la ejecución de una lectura estética. En nuestro cerebro existe un área de reconocimiento visual específica para las formas visuales y, sólo por ello, parece admisible pensar que, en la lectura, la forma de las letras puede ser un ingrediente de la experiencia estética: si esto es verdad para cierta poesía, no se trata sin embargo sino del ejemplo más básico de cuantos pueden ofrecerse en el campo de la relación entre lo visual y lo estético en contexto poético. Y, como se verá, la implicación de lo perceptivo no comprende solo lo visual, ni lo visual se acaba en los signos físicos de la escritura.

El amplio arco de recorrido que la historia de la estética cubre entre los extremos llamados armonía y disonancia tiene las mismas dimensiones que el abrazado por la capacidad de adaptación de nuestro cerebro. La historia de la estética es una progresiva exploración de los umbrales más allá de los cuales la disonancia no puede ser integrada: por exceso o por defecto de disonancia — por absoluta disconformidad o conformidad a un patrón-, los paradigmas artísticos entran en crisis y cambian. El "potencial de excitación" de una obra artística (Martindale, 1990) debe ser alto, y excitar con ello modos cognitivos primordiales — no 
dependientes de la razón-, pero no sobrepasar ese umbral a partir del cual no es posible reconocer algún grado de conformidad y armonía. La historia de la estética se reproduce en la vida estética personal de cada individuo: todo aprendizaje es una absorción de modelo, toda exploración una transgresión de la norma; el comienzo de todo ejercicio estético se basa en el reconocimiento de la armonía (en cualquiera de sus versiones: repetición, simetría, resonancia, regularidad...) pero parece ser que tal ejercicio sostenido desarrolla un gusto por la disonancia y sus desafíos de integración. Ciertamente el gusto estético puede estar relativamente vinculado al carácter del individuo, pero sobre todo lo está a su habituación en el ejercicio de integración cerebral de la disonancia, y ese umbral puede ampliarse mediante aprendizaje: un aprendizaje del cerebro como muchos otros, un ejercicio de plasticidad. Los procesos neuronales implicados en la experiencia estética y referidos a la armonía no son privativos de la misma, pertenecen a los modos de percepción y cognición generales. Sin embargo, lo disruptivo y disonante en la vida cotidiana suele considerarse aleatorio, mientras que en el arte la experiencia estética trata de leerlo con algún grado de estructura, coherencia y deliberación (aunque sea coherencia a contrario), y el cerebro se comporta semióticamente, busca sentido, construye sentido. Un sentido que se mide precisamente con respecto a la ruptura de la armonía (diferencia, variabilidad, oposición...) (Armstrong, 2013: 49 y 50).

En el campo de la neuroestética, existen diferentes posiciones de comprensión del arte. Si Changeux (2008) defiende la experiencia estética como armonía y el arte como búsqueda de regularidades, Ramachandran incluye también en ambos la disonancia (2012: 321-324). La curiosa explicación que este ofrece asocia el gusto por la regularidad y la simetría a un impulso biológico de selección de las parejas según el cual tendemos a reproducirnos con quienes tengan menos defectos provocados por parásitos (esta señal de salud garante de la prosperidad de la especie está también relacionada con el hecho de que la simetría de los cuerpos favorece su capacidad de movimiento rápido en la caza y en la huída). 
Pero Ramachandran propone que la preferencia de regularidad atañe sólo a los objetos (y a su reconocimiento, realizado por la "vía visual llamada del Qué") y no a las escenas (procesadas por la "vía visual del Dónde"), en las que soportamos mal la simetría y la coincidencia, que al cerebro le parecen poco explicables. De modo que el arte estaría biológicamente tensado entre esos dos polos de armonía y disonancia, sin que se conozcan muy bien los procesos neurológicos que nos permiten combinarlos. Pero es comprensible que esta tensión sea necesaria para que tanto el cerebro como el arte sean dinámicos y se configuren como sistemas vivos (real y metafóricamente): para que no entren en la entropía a la que se ven condenados los sistemas cerrados.

Ramachandran (2012: 305-306) y Zeki (2005) defienden que el arte — se refieren a la pintura moderna - aísla y elige para representar el mundo ciertos ingredientes de la visión - la orientación de las líneas o el color, por ejemplo- desechando el resto. Aunque volveremos a este asunto páginas adelante, es momento de señalar que ese rechazo de la representación mimética global en favor de solo alguno de sus componentes traduce una opción por la disonancia que se vincula de manera estrecha a la percepción visual. De donde cabe deducir una disposición para la disonancia estética derivada del propio aparato perceptivo — fragmentado en áreas visuales especializadas - que sostiene nuestra cognición. Y - como también se precisará - este asunto no es menor tampoco para lo que se refiere a la lectura poética y su capacidad de suscitar extrañamiento.

En el último siglo y medio, la opción de la disonancia ha ganado también progresivamente adeptos en el campo de la teoría estética. El ejemplo que aquí interesa es el de Shklovski, cuyo concepto de "desfamiliarización" reposa asimismo sobre la singularidad de lo percibido. Pero se diría que, donde Shklovski considera necesario recabar el concurso de la técnica y el artificio para provocar una desautomatización que suscite el "extrañamiento", la neuroestética nos está señalando más bien un trabajo de selección y aislamiento de los componentes de nuestra cognición. De modo más ecuánime podría decirse que, desde el punto de 
vista cognitivo, la desfamiliarización - la captación de disonancia respecto de un patrón- incide en los propios estratos o módulos que naturalmente la construyen, mientras que, desde el punto de vista de la cultura, el dispositivo de "extrañamiento" sería un añadido de naturaleza artificial. Restar o añadir: seguramente ambas opciones entran en el juego del arte, de la literatura, de la poesía. Pero la perspectiva de estudio aquí elegida con respecto a la lectura — a la lectura poética — es únicamente de orden cognitivo, y por ello se dirige hacia lo que cabe llamar un desaprendizaje: una desautomatización de la integración de los procesos activos en la lectura.

\section{DESINTEGRACIÓN E INTEGRACIÓN ESTÉSICA}

No parece descabellado concebir que la técnica y la artificialidad generadora de disrupción y conducente a un extrañamiento de tipo cultural puedan ser objeto de aprendizaje consciente en el terreno literario. Sin embargo, la remisión a procedimientos más básicos concurrentes en la cognición parece ser más bien fruto de una exploración poco consciente en el orden de la experiencia sensomotora de cada sujeto poético. La estética de la poesía moderna está fuertemente vinculada a esta práctica interiorizada, y aunque periódicamente existen movimientos estéticos contrarios a ella, su tradición es reconocible desde Baudelaire hasta Bonnefoy (ejemplos tan dispares en el campo literario francés que dan idea de la transversalidad de esta poética cognitiva). Se podría decir de esta poesía moderna algo semejante a lo que dice Zeki del arte pictórico:

A medida que el arte ha entrado en una época más moderna, aunque ha permanecido fiel a su misión de representar [objetos] esenciales y constantes, cada vez se ajusta más a la fisiología de las áreas visuales, y en particular, a las respuestas de las células individuales que se encuentran en ellas, puesto que la función de estas áreas es, asimismo, destilar los elementos esenciales del 
mundo visual (2005: 123).

Será precisamente un poema del "poeta de la vida moderna" Baudelaire - "À une passante" ["A una transeúnte"] — el que en estas páginas servirá de campo de pruebas para la interrogación cognitiva de la lectura poética, interrogación centrada en lo visual sin perjuicio de otros modos perceptivos, pues la lectura es una experiencia mental multimodal.

La experiencia estética de la lectura poética se enraíza en una multimodalidad distribuida en la doble naturaleza - material y mentalde la literatura. Con ser de gran importancia, la materialidad que no tiene en ella el mismo peso que en las artes plásticas, pues la literatura cuenta tanto con perceptos como con conceptos derivados de su naturaleza lingüística significante. En efecto, la percepción directa de la materialidad literaria (sonidos y disposición visual de la grafía de los signos) es simultánea a una segunda articulación del percepto en la que este se emancipa de la materialidad (Ouellet, 2000). Ahí el percepto procede de la comprensión lectora - no de la experiencia física directa - y de la memoria de la experiencia física de percepción evocada - una percepción ya mediada por el entendimiento- . Ouellet señala así que la literatura es conocimiento cruzado con sensaciones, episteme ligada a estesia, concepto y percepto juntos, reunidos en imagen mental. La imagen mental se define como concepto anclado en el terreno del percepto - y cabe reseñar aquí que esta definición es gemela a la de la metáfora conceptual concebida por Lakoff y Johnson (1986), para quienes todo concepto es metafórico, es decir, tiene ese anclaje perceptual (y sensomotor) del que habla Ouellet-

Toda experiencia de imagen mental suscitada por la lectura literaria depende de una experiencia estésica virtual del lector basada en su experiencia estésica real previa, y conserva de ella patrones perceptivos — esquemas de imagen (Johnson, 1991) — e impronta neuronal. Hay pues experiencia estésica — con sus ingredientes de armonía y disonancia- en la imagen mental suscitada por la lectura. Pero, en literatura y en especial en poesía, esta experiencia está acompañada — como ocurre en todo arte- 
de una experiencia estésica suscitada por la percepción de la materialidad visual y sonora del texto escrito y leído. Y cabe suponer que, puesto que el cerebro no es capaz de producir dos imágenes mentales al mismo tiempo, ambas estesias entren en integración, del mismo modo que lo hacen los dos inputs en la teoría cognitiva de integración conceptual de Turner conocida como blending (2002), proceso en el curso del cual preceptivamente habría de surgir "algo nuevo".

Bajo el nombre de "forma-sentido" (Meschonnic, 1970), esta integración ha sido objeto de análisis en la poética literaria, donde el "sentido poético" podría también ser análogo a la novedad surgida en la imagen mental resultante del blending. Estos paralelismos sugieren la rentabilidad de un acercamiento de la ciencia cognitiva al ámbito de los estudios poéticos, donde la lectura poética no persigue altura conceptual sino eficacia del trabajo de integración —del que no están ausentes disensiones y negociaciones - de las dos series estésicas. Series estésicas a las que cabría describir del modo siguiente: en la primera, la lectura proporciona imágenes mentales (representaciones paisajísticas, organizaciones narrativas, construcciones procedentes de los elementos narrativo-descriptivo del texto) construidas sobre esquemas de imágenes disponibles en la memoria del lector y que en última instancia remiten a la experiencia sensomotriz vivida físicamente por él; esas imágenes mentales se encuentran modificadas también por esquemas aportados por la cultura en sentido amplio. En la segunda serie estésica, la experiencia auditivo-visual del lenguaje en su materialidad puede ser directa (escuchar un texto, ver sus signos escritos) o virtual (la lectura silenciosa no deja de despertar zonas neuronales sensibles al sonido). Esta experiencia del material sonoro o gráfico percibido en su temporalidad sonora y en su disposición espacial también viene marcada por esquemas que remiten a la experiencia sensomotriz corporalmente vivida.

Aunque la lectura poética trabaje en la integración, la voluntad analítica de estas páginas demanda que los procesos relativos a ambas series estésicas sean presentados de manera independiente al menos en su 
punto de partida - y que se muestre después su convergencia-. Procede también insistir en que todos leemos en función de nuestras capacidades asociativas, de nuestro procesamiento sensorial presente y pasado y del almacenamiento de representaciones mentales bajo forma de circuitos neuronales aproximadamente repetibles. Por ello toda lectura poética posee aspectos no forzosamente compartidos, y la que aquí se propone sobre el poema de Baudelaire tampoco tiene por qué ser excepción.

\section{LEER LA FORMA DEL SIGNO}

Parece una obviedad decir que leer los signos de una escritura requiere del concurso de la audición además del de la vista, pero ni eso fue así siempre — no antes de la escritura alfabética — ni tampoco es evidente en nuestras prácticas de lectura silenciosa. Dice Quignard ambiguamente de esta lectura "ambrosiana":

En el curso de la lectura, se dice que, a veces, una voz silenciosa aparece. Evidentemente no nace del libro. Pero no la articula el cuerpo. Se empareja con el ritmo de la sintaxis y sin hacer sonar las palabras moviliza sin embargo la garganta, el aliento, los labios. Parece que, aunque inmóvil, todo el cuerpo se haya puesto a seguir una cierta cadencia, que no controla pero que el libro le impone: la lengua resuena en silencio en las marcas sintácticas, el cuerpo jadea un poco, y es un tarareo muy lejano (2016a: 107).

La neurociencia, por su parte, afirma más claramente que "podemos escuchar nuestra propia 'voz interior' pronunciando palabras mentalmente. Los estudios recientes de resonancia magnética funcional han asociado ese componente con una mayor actividad metabólica en la corteza auditiva, incluidas las áreas selectivas de la voz" (Perrone-Bertolotti et al., 2012). Parece ser que aprender a leer fortalece la conectividad entre las áreas 
visual y auditiva a base de asociarlas repetidamente. Con la práctica, esta conectividad permitiría una activación directa de la corteza auditiva incluso en el caso de la lectura silenciosa (Dehaene, 2007: 53). Por otro lado, una palabra no se lee globalmente, siempre se leen sus partes, aunque un lector experto lo mismo tarda en leer una palabra de tres letras que una de ocho (la quinta parte de un segundo): las neuronas se distribuyen la tarea de leer los diferentes segmentos de la cadena de letras, y lo hacen simultáneamente (Dehaene, 2011: 49). Así pues, uno se pregunta si lo que oye el cerebro lector no es un notable guirigay. Sucede sin embargo que todos tenemos la sensación de que la lectura silenciosa de la poesía hay que hacerla más despacio que la de la prosa, como si necesitáramos ver todas las letras de las palabras para que en la voz interior suenen como en la realización sonora en voz alta. Esta es quizá una razón de que la poesía haya sido medida durante mucho tiempo, pues la medida impone ese tiempo de realización a la voz interior. Pero si la poesía moderna ha abandonado progresivamente metro y rima, hay entonces que suponer que los ha reemplazado por otras estrategias de ralentización de la voz interior; y es de sospechar que esas estrategias sean visuales, aunque quizá no tengan ya que ver con la visualidad de la grafía sino con la de la imagen mental que suscitan las palabras. Esta vinculación de la fonología - incluso en la voz silenciosa - con los aspectos visuales se asienta sobre las propias vías de la lectura descritas por la ciencia cognitiva.

\subsection{Competencia y rentabilidad poética de las dos vías de lectura}

Explica Dehaene (2007) que dos son estas vías: la del sentido (léxica) y la de los sonidos (fonológica). Toda lectura necesita de ambas para poder abordar un texto, y ambas alternan y colaboran: la vía fonológica atribuye sonidos a las palabras antes de reconocerles un sentido y permite al lector enfrentarse de ese modo a los términos desconocidos leyéndolos en función de reglas de pronunciación interiorizadas. La vía léxica se ocupa 
de las palabras conocidas - algunas con pronunciación muy irregular en algunas lenguas - y se encarga también de deshacer las ambigüedades de los homófonos — que no siempre se escriben del mismo modo- - La localización del sentido por vía semántica parece obviar la realización acústica interna de la palabra; de modo que no conviene particularmente a lectura poética, que buscará restituir para el caso la vía fonológica. Como ya se intuye, la repartición de tareas permite la eficaz convivencia de ambas vías, pero no excusa sus puntuales desacuerdos.

Uno de los casos más representativos de la pugna entre vías de lectura es el del rébus, muy extendido en lenguas tendentes a la homofonía - como el francés - y consistente en una realización sonora única para tramos de texto gráfica y semánticamente diferentes: nez rond, nez pointu, main / Néron n'est point humain, dice el más clásico de los rébus franceses. En contexto poético, la frecuencia de rébus fragmentarios es grande, pues se activa una presión de la vía fonológica sobre la vía léxica (Gamoneda, 2014: 434) que "descubre" secuencias fónicas significativas que no respetan la integridad gráfica de las palabras. Sostenidas por el contexto - integrando su sentido, por ejemplo, en un campo semántico ya presente en el texto- estas secuencias fónicas potencian procesos inestables de lectura, pues proporcionan ambigüedades en las imágenes mentales, obligan al lector a una actividad interpretativa. La colaboración entre las dos vías simultáneas de lectura en todo texto adquiere en poesía una tensión que es extrañamiento lingüístico para el lector. Esta tensión cristaliza en el rébus, pero, por supuesto, no es esta la única figura en la que ambas vías se disputan.

Un buen lector desentraña a la vez fonemas y morfemas de palabras, es decir, usa las dos vías de lectura. Pero cuando un niño empieza a leer, lo hace a través de la vía fonológica — silabea — y solo más tarde llega al estadio en que puede pasar de la cadena de letras al sentido de la palabra sin que intermedie la pronunciación (oral o simulada mentalmente). Se diría que la lectura poética recupera una preeminencia fonológica que pertenece a estos comienzos de la lectura, donde sin duda los aspectos orales son 
puente necesario entre la captación visual del signo y su afectación de sentido.

Pero el caso es que después, en la adquisición del paso directo de lo escrito al sentido, el cerebro se acostumbra a descomponer en morfemas (lexemas, desinencias) las palabras: las palabras se leen descompuestas en partes; y lo curioso es que tales partes no siempre están bien recortadas: el ojo lector lo mismo recorta "re-volv-er" (donde se puede reconocer a posteriori la corrección de la división morfemática) que "re-mar", donde nada justifica que haya un morfema de repetición "re-", pues la etimología de la palabra señala que esta procede del latín remus. Errores como este cometido por la vía léxica - muy frecuentes - pueden desestabilizar el sentido, que queda flotando entre dos atribuciones semánticas: no es que la palabra deje de significar "mover los remos en el agua para hacer avanzar una embarcación", es que, además, esa agua en la que se mueven es comprendida como agua de "mar". Para llegar a esta comprensión y a esta interesada incorrección de la distinción morfemática, habrá valido que un contexto de tema marino o una palabra con el lexema "mar" correctamente distinguido haya precedido visualmente a la palabra "remar": se habrá producido de este modo un amorçage — donde una primera cadena de letras o sonidos facilita la lectura de otra segunda, pues comparten un mismo morfema aunque no tengan entre ellas una relación de sentido (Dehaene, 2007: 49) — que explica algunos fenómenos poéticos, y que indica que uno de los caminos de la lectura poética no distingue las piedras de su empedrado: fragmenta arbitrariamente el cuerpo de las palabras y rompe la univocidad del signo lingüístico, de modo que el sentido - poco domado - aparece encabalgando significantes. La lectura poética extrae esta libre indisciplina de un error en el sistema de reconocimiento visual sobre el que se basa la vía léxica de lectura.

\subsection{Ver y escuchar un verso}

En contexto de lectura, se llama granularidad al tamaño de los 
elementos que transcriben la lengua oral: fonemas, sílabas, palabras. Puede entonces decirse que la lectura poética pone en cuestión la granularidad establecida de las lenguas. La poesía simbolista, por pluma de Mallarmé, expresó esta convicción al proponer el verso como unidad poética y no la palabra - una convicción que ha dejado su huella en toda la poesía moderna y en su lectura-. Una "granularidad poética" no reposaría pues siempre sobre estructuras morfemáticas simples y su sentido no podría estar recogido en un diccionario de palabras. Antes bien, esta granularidad contemplaría conglomerados de morfemas organizados en otro nivel estructural (ritmos, rimas, asociaciones a nivel versal, anagramas, traslaciones de esquemas sonoros o visuales...) con sentido emergente: una suerte de representación diagramática en la que se cruza la percepción, la experiencia corporal, la comprensión como acción del ojo, de la mano o del cuerpo y el sentido de los morfemas de la lengua. La unidad de lengua legible - tanto en su dimensión fonológica y visual como de sentidosería el verso - cuando no el poema en toda su extensión-.

Sucede aquí, como en el aprendizaje lector más temprano, cuando el niño todavía presenta "una tendencia espontánea a tratar cada objeto como un todo" y, del mismo modo, "no ve forzosamente que las palabras están constituidas por letras" (Dehaene, 2011: 41). Cuando alguien aprende un alfabeto nuevo, si no se le explican los constituyentes de los signos verbales, si se le presentan las palabras como formas globales, no sólo aprende menos sino que también activa un área cerebral inadecuada en el hemisferio derecho en lugar de hacer lo propio con el área visual de las palabras - que se encuentra en el hemisferio izquierdo en una región bien precisa del córtex visual (Dehaene, 2011: 42-43)—. Así pues, la consideración más global de la escritura que se da en la lectura poética —el verso como unidad, por ejemplo_- podría también inducir esa activación inadecuada del hemisferio derecho que considera globalmente la forma del objeto poético.

Hay también una temprana fase en la que el aprendiz de la lectura sigue transitoriamente tratando las letras como si fueran objetos invariantes 
a pesar de su posición $-\mathrm{y}$ por ello confunde las letras en espejo, por ejemplo la "p" y la "q", o la "d" y la "b"—. Quizá sucede algo similar en la lectura poética, pero trasladado a un plano más global o estructural - otra vez el verso, o incluso el poema entero-, y así, el lector reconoce simetrías y paralelismos gráficos $-\mathrm{y}$ fónicos - no significantes en el lenguaje común, pero que sugieren asociaciones significantes: manipula mentalmente estructuras gráficas o fónicas como si fueran objetos y reconoce la invariancia de los mismos (o su semejanza) más allá de sus posiciones rotadas o invertidas. La lectura poética —así lo querían al menos los simbolistas - parece efectivamente manipular el verso como un objeto, desaprendiendo en parte su constitución morfemática, es decir, dando una vez más la preeminencia a la vía de lectura fonológica sobre la léxica, fundando directamente sobre la primera un nivel de granularidad superior al que corresponde a la lengua en cuestión.

Esta idea de Mallarmé - no expresada, naturalmente en los términos aquí empleados - formula una intuición activa ya de facto en Baudelaire $-\mathrm{y}$ atisbada en múltiples predecesores-. À une passante comienza con un verdadero tour de force de demostración del verso como unidad de sentido poético2: "La rue assourdissante autour de moi hurlait." se cierra

\footnotetext{
${ }^{2}$ A une passante - La rue assourdissante autour de moi hurlait. / Longue, mince, en grand deuil, douleur majestueuse, / Une femme passa, d'une main fastueuse / Soulevant, balançant le feston et l'ourlet; // Agile et noble, avec sa jambe de statue. / Moi, je buvais, crispé comme un extravagant, / Dans son oeil, ciel livide où germe l'ouragan, / La douceur qui fascine et le plaisir qui tue. // Un éclair.. puis la nuit! - Fugitive Beauté / Dont le regard m'a fait soudainement renaître, / Ne te verrai-je plus que dans l'éternité? // Ailleurs, bien loin d'ici! trop tard! jamais peut-être! / Car j'ignore où tu fuis, tu ne sais où je vais, / Ô toi que j'eusse aimée, ô toi qui le savais! [A una paseante - La calle tumultuosa en torno a mí bramaba. / Alta, enlutada, esbelta, en dolor majestuoso, / una mujer pasó recogiendo, meciendo / con su mano fastuosa festones y volantes. // Era ágil y noble en su pierna de estatua. / Yo, entretanto, bebía, crispado extravagante, / en su ojo cielo lívido que anuncia el huracán-, / la dulzura que hechiza y el placer que mata. // Un relámpago... noche - Belleza fugitiva / cuya mirada me hizo, de pronto, renacer: / ¿ya no volveré a verte hasta la eternidad? // ¡En el allende, lejos, muy tarde o quizás nunca! / Yo no sé a dónde huyes, tú ignoras a dónde voy, / ¡tú, a quien hubiese amado, tú, que bien lo sabías!] (La traducción es de la autora de este artículo).
} 
con un punto, en el interior del cual la significación de la frase sobre el ruido ensordecedor de la multitud callejera ${ }^{3}$ se modifica al considerar la composición fonológica del verso entero: /laryasuRdisãtotuRdəmwayRl€/. Composición en la cual se distingue una estructura duplicada/uRd/ ("assourdi-" "autour de") y una estructura en espejo/lRya//ayRl/abriendo y cerrando el verso. De modo que esas estructuras fónicas — que incluyen un fonema / R/ insistente - esquematizan ideas de repetición y de cercamiento que refuerzan el lexema "autour" ["en torno a"], con el resultado de que el verso ahora significa que el exceso de ruido no sólo es ensordecedor sino que también cerca y asedia insistente y quizá amenazadoramente a un sujeto poético que se encuentra en su centro - y este último sentido es "nuevo" y emerge de la integración de una imagen mental y una imagen sonora-.

El trayecto fónico que abre y cierra el verso esboza además la estructura quiasmática de encuentro y divergencia que — como se verá más adelante — rige múltiples organizaciones significantes del texto, amén de recoger el esquema narrativo que cuenta el poema: una mujer se acerca, se cruza con el poeta, intercambia con él una mirada y vuelve a alejarse. Las trayectorias - físicas o vitales - de ambos sólo se interseccionan una vez, y los versos del segundo terceto marcan ese lugar con un "où" ["dónde"] que es el emplazamiento sintáctico en el que el "je" y el "tu" coinciden solo para decir la ignorancia mutua de sus respectivos caminos: “car j'ignore où tu fuis / tu ne sais où je vais". Esta divergencia que relata el poema se anticipa y miniaturiza fónicamente ya en ese primer verso, que cumple de este modo la ley del íncipit.

\subsection{Gesto y lectura}

Al avanzar en su aprendizaje de lectura, el niño deja de confundir

\footnotetext{
${ }^{3}$ Sin olvidar el de las obras públicas de ese momento de transformación urbana parisina: ¿por qué no las obras de la construcción de la Gare de Lyon de París en 1855, año de publicación del poema?
} 
las letras en espejo, y lo hace entrenándose en el gesto de escritura de esas letras - "la letra con gesto entra", se diría-. Parece ser que entonces se pone en funcionamiento otra zona lectora cerebral:

Contrariamente a la región "ventral" del cerebro que nos sirve para reconocer los objetos, la vía "dorsal" que enlaza la visión del córtex motor y orienta nuestros gestos distingue precozmente la orientación de los objetos [...] El reconocimiento del gesto desempeña igualmente un papel esencial en el descifrado de la escritura manuscrita (Dehaene, 2011: 46).

Esta gestualidad está asociada a los movimientos de los ojos: el ojo recorre la letra como reconociendo el gesto de la mano que la ha trazado: el ojo ejecuta el gesto de la mano. Aunque cesa con el tiempo y con la destreza en la lectura, la lectura poética recupera algo de esta vinculación entre reconocimiento de lo escrito y gestualidad, pero generalmente no sólo referida al grafema sino vinculada al nivel fónico y a la imaginación visual que suscita el poema. Esta expansión de lo gestual a todos los ámbitos de percepción — real y figurada - activos en el poema es característica de la lectura poética.

La temprana asociación de gesto y forma gráfica del signo no es sólo propia del aprendizaje lector individual sino también de la historia de la escritura. En su inicio los signos eran pictográficos (no sólo el sistema jeroglífico egipcio sino también el cuneiforme sumerio): tenían carácter icónico, se parecían a lo que representaban, evocaban su contorno físico o su dinamismo y así la escritura reciclaba en el cerebro circuitos utilizados para el reconocimiento de objetos. La escritura logográfica (de representación abstracta del concepto) llegó más tarde, incorporando además un aspecto logosilábico (representaba sílabas de la producción oral; en sumerio, concretamente la primera sílaba de la palabra); para ello, la escritura utilizó el principio del jeroglífico, de modo que el símbolo logográfico de un pájaro "podía usarse para expresar el concepto pájaro 
o como fonema" (Wolf, 52). Esta doble concepción - logográfica y logosilábica - aparece también en lenguas actuales como el chino, o repartidas en los dos sistemas de escritura japonesa kanji y kana.

Para la experta en lenguaje y lectura Maryanne Wolf, cuando el niño está aprendiendo a leer atraviesa una fase que es "como una 'etapa' logográfica [...]: lo que el niño entiende, de forma muy parecida a como lo hacían nuestros antepasados lectores de sellos de cálculo, es la relación entre el concepto y el símbolo escrito" (Wolf, 2008: 117). Durante esta etapa el niño estaría utilizando los mismos circuitos cerebrales que el lector chino (o del kanji japonés), algunos de los cuales están en el hemisferio derecho del cerebro, de modo que habría una activación bihemisférica de las zonas visuales (Wolf, 2008: 54, 82).

La lectura poética conserva rastros de un comportamiento logográfico inserto en la general naturaleza alfabética de la escritura occidental. Quiere ello decir que la firmemente establecida representación gráfica de los sonidos alberga también una posibilidad de lectura de representación gráfica abstracta del concepto: como si la lectura poética ejecutara en sentido inverso - recuperara desaprendiendo - una historia de la lectura personal y humana. En los poemas hay grafemas en los que el ojo distingue aún la huella de alguna forma o de algún dinamismo proveniente del concepto (a título de ejemplo, recuérdese "le O de l'ouvert" en L'été langue morte, de Bernard Noël; la "s" de "Sitôt pétris, sitôt soufflés, / Maître Serpent les a sifflés," en Le serpent, de Valéry).

Además, la lectura poética es capaz de añadir una dimensión logofónica que se engarzaría con la representación logográfica de la letra. Pues es obvio — en el último ejemplo de Valéry_ que la "s" carga en su lectura una forma dinámica imitativa de la serpiente, mientras que " $\mathrm{s}+\mathrm{f}$ " se encarga de la imitación sonora del amenazante sonido que el animal emite - siseo en español; sifflement en francés—-, fenómeno conocido con el nombre de "armonía imitativa".

La amplitud y la complejidad del comportamiento logográfico y logofónico de la lectura poética pueden ser mucho mayores, y el poema de 
Baudelaire da muestras de ello. En À une passante, encontramos en el primer cuarteto la secuencia gráfica -stueuse, que para el lector reproduce visual y sonoramente el movimiento de la falda de la passante, quien avanza con paso ritmado por la respiración de las comas del verso ("Longue, mince, en grand deuil, douleur majestueuse"); un ritmo reconocible rápidamente como bimembre en las pausas del cuarto verso ("soulevant, balançant, le feston et l'ourlet") cuya simetría recogen los cuatro términos (en los que se reconocen dos a dos diferentes aspectos repetitivos: categoría gramatical, morfología, proximidad semántica). Reiterada íntegramente en majestueuse y fastueuse, la secuencia gráfica-stueuse también se encuentra fragmentariamente en feston, que no sólo repite el sonido sino que traduce en significado (bordado en forma de ondas que adorna el borde de una tela) lo que en los otros dos términos era gráfico y sonoro movimiento ondulatorio de un borde - borde localizado físicamente en el poema en el final de los versos, portadores de la rima en -stueuse- - Se aprecian pues traslaciones entre lo visual a lo auditivo tanto en la serie visual real (caracteres visibles y pronunciables, forma versal del poema) como en la serie visual de la representación mental (escena de la passante avanzando con la falda sostenida por la mano $)^{4}$. La secuencia de asociaciones podría ser entonces la siguiente: la representación mental de la escena en la que la passante avanza con ritmo marcado y movimiento ondulatorio de falda funciona como amorçage gestual para el recorrido dinámico que el ojo hace del grafema "s" (majestueuse, passa, fastueuse, soulevant, feston) asociado a la realización fónica de la secuencia recurrente -stueuse: (/s/ sorda + interrupción de la sibilante por la interdental /t/ que marca pausa dentro del movimiento + /z/ sonora que prolonga el movimiento. Y cabe añadir que la percepción dinámica de grafemas y fonemas que el gesto propicia alcanza e incluye también en su contexto a la palabra statue ["estatua"], situada en

\footnotetext{
${ }^{4}$ Otra ocurrencia de la permeabilidad entre sonido y sentido: la secuencia gráfica "ourlet" del verso 4 -término que significa "dobladillo", en el borde de una falda, por ejemplomueve sus letras con revuelo, de manera que caigan en otro orden dentro de la palabra “douleur" del verso 2.
} 
el quinto verso; y lo que en este término parecería paradójico — evocación gráfica y sonora de movilidad /st/ + contenido semántico de inmovilidadpronto se verá que adquiere coherencia, precisamente porque una de las claves de interpretación del poema es la voluntad de dotar de movimiento a la representación estatuaria de la Beauté baudelairina.

La dimensión logográfica y logofónica de la lectura poética hace sospechar el concurso de las áreas activas en la capacidad de la memoria motriz y una implicación importante de las áreas del hemisferio derecho, tal y como ocurre en el caso de las escrituras logográficas y en ciertas etapas del aprendizaje infantil de la lectura. En el ejemplo expuesto se aprecia también un esquema de imagen dinámico procedente de la experiencia corporal que informa tanto la imagen mental como la percepción visual del grafema y de su realización fónica. Toda imagen mental o auditiva es un acto mental, todo conocimiento es gestualidad: responden a una exploración sensomotriz simulada (Olivier, 2012: 75). Y, además, puesto que el poema sitúa al sujeto poético como espectador de esta escena en la que la mujer avanza andando de tal manera, no es ocioso suponer que el funcionamiento de las neuronas espejo pudiera propiciar en el cerebro del poeta ese esquema de imagen dinámico que impregna el textos.

\section{LEER EL CONTENIDO DEL SIGNO: LA IMAGEN MENTAL}

Aunque las líneas precedentes han abordado algunas cuestiones relativas a la imagen mental, es al hablar de una lectura del contenido del signo cuando esta se vuelve central. A pesar de lo dicho en el párrafo anterior, es preciso señalar que la imagen mental que suscita la lectura

\footnotetext{
${ }^{5}$ Las neuronas espejo (Rizzolatti y Sinigaglia, 2008) se encuentran en una parte del córtex cerebral que participa en la preparación del movimiento. Estas neuronas se activan tanto cuando se realizan ciertos actos motores como cuando se observa a alguien que los realiza. Las neuronas espejo funcionan pues como si fueran a un tiempo motoras y sensoriales. Changeux afirma que las neuronas espejo pueden intervenir también en la experiencia estética (2008: 138).
} 
no es exactamente la misma que obtiene un espectador en el mundo real. La imagen mental en el cerebro del espectador - llamarla imagen es una convención, puesto que no consiste sino en activación de circuitos neuronales - procede de la imagen visual — que se construye, a su vez, mediante un laborioso y fragmentario concurso de las áreas visuales-, a la que hay que sumar ciertas rectificaciones de interpretación que tienden a completarla y a producir integración de todos sus componentes rectificaciones que están en función de la memoria y los hábitos perceptivos de ese espectador- Sin embargo, la imagen mental del lector depende en parte de la percepción transmitida (forzosamente incompleta) por el texto y procedente de la percepción de su autor como espectador; y en parte también depende de la memoria perceptiva del propio lector, asentada sobre su historia y su experiencia corporal del mundo.

À une passante proporciona en su primer cuarteto la descripción de una imagen que va surgiendo - la de la mujer - y esta circunstancia permite analizar el tipo de imagen mental que el lector construye. El segundo verso - "Longue, mince, en grand deuil, douleur majestueuse" — sugiere, respecto del primero, una organización perceptiva — procedente de la psicología de la Gestalt — conocida como "principio de discriminación fondo-figura". Ciertamente, el primer verso habla de sonido ensordecedor, pero lo sitúa en una calle; es más, personifica a la calle como productora de un sonido con carácter humano - "La rue assourdissante autour de moi hurlait" - Sobre este fondo sonoro y visual confuso aparece en el segundo verso una "figura" con todas las características exigibles para su distinción del fondo: tiene forma y contorno, resalta, se percibe como una masa con volumen, su color es más denso que el del fondo.

Como ha quedado dicho con anterioridad, la neurología de la visión enseña hoy que existe una vía visual dorsal que se ocupa de procesar la posición y el movimiento del objeto (Vía del Dónde) y una vía visual ventral que procesa su forma y su color (Vía del Qué). Además, la visión es modular y se procesa en múltiples áreas visuales, que pueden tener partes dorsales y ventrales y no poseen jerarquía de importancia ni 
están integradas bajo una sola área rectora, pero sí necesitan un tiempo de procesamiento diferente que las ordena. V1 (corteza visual primaria) y V2 distribuyen señales visuales selectivamente a otras áreas visuales (Zeki, 2005: 34). Un gran número de células del área V1 son selectivas de orientación — "son los bloques constituyentes de la elaboración neurológica de las formas" (Zeki, 2005: 133) aunque no se sepa cómo las construyen - , pero éstas también se encuentran en V2 y V3; el color se procesa en V4 y en ciertas delgadas bandas de V2, y el movimiento en V5 (pero también en V3 y con intermediación de bandas anchas de V2). Las interconexiones son múltiples, pero puede concluirse que el color se percibe antes que el movimiento - entre 60 y 80 milésimas de segundos-, y que las ubicaciones se perciben antes que los colores, colores que, a su vez, se perciben antes que las orientaciones. De modo que - simplificandoquizá pudiera resumirse así el orden: ubicaciones $>$ colores $>$ orientaciones $>$ forma $>$ movimiento.

Zeki considera el arte como una extensión de las funciones visuales del cerebro, una búsqueda en la que el artista analiza - más o menos inconscientemente - los atributos de la visión (2005: 41). Aunque el ordenamiento temporal de esos atributos se produce en milisegundos, hay obras de arte plástico que se especializan en transmitir alguno de los procesamientos de la escena visual, quedando los demás descartados o en segundo plano. Esta separación y selección de procesos que tienen lugar de modo casi sincrónico es justamente uno de los terrenos de extrañamiento en los que han avanzado prospectivamente vanguardias como el cubismo o la pintura cinética — con un pulso de interrogación cognitiva análogo al de la poesía moderna y la posterior poesía vanguardista-. Unas veces latente y otras latiendo, este pulso ha atravesado también la narrativa del siglo XX, acelerándose en movimientos literarios como el Nouveau Roman francés ${ }^{6}$. Pero de modo general y continuado es el género de la poesía el que ha

\footnotetext{
${ }^{6}$ Ver sobre esta aproximación a la percepción visual desde perspectiva cognitiva mi artículo con título "La descripción especular. Lectura neurocognitiva de La Jalousie de Robbe- Grillet” (Gamoneda, 2016).
} 
ofrecido desde finales del XIX un campo altamente sensible al tratamiento de los atributos de la visión en la imagen mental que el lector construye tras la estela de la del autor.

Al contrastar en el poema $A$ une passante el orden de aparición de los atributos de la visión más arriba resumido, parece que Baudelaire en parte lo respeta y en parte lo trastoca, pues pone primero la forma, luego el color y finalmente el movimiento: "Longue, mince, en grand deuil, douleur majestueuse, / une femme passa". El tiempo que tardan en unirse todos los atributos en experiencia unitaria es de más de un segundo (Zeki, 2005: 86), pero en la descripción el poeta requiere de verso y medio para componer la unidad: solo al culminar el proceso ve que se trata de una mujer. Precisa Zeki que entre los múltiples sistemas que sirven para procesar diferentes atributos de la escena visual, los hay tan "especializados como para distinguir entre la versión estática y la versión dinámica de la misma forma" (2005: 95). En ese sentido, no es insignificante que esta passante se dé a conocer precisamente en el momento en el que se señala su condición de forma dinámica — "une femme passa"-. Y tampoco lo es que el poeta la reconozca no solo como mujer sino también como objeto amoroso precisamente a causa de su movimiento: la llama "fugitive Beauté", Belleza que se mueve y que por tanto no es fijamente estatuaria (su "jambe de statue" es "agile"); su movimiento contrasta pues con la Beauté del otro conocido poema baudelairiano ${ }^{7}$, donde la Beauté no solo "hai[t] le mouvement qui déplace les lignes" ["odi[a] el movimiento que desplaza las líneas"], sino que es inaccesible, incomprensible y reduce al enamorado poeta al silencio impotente de quien no puede conocerla ni poseerla. Agnosia visual de belleza en reposo, podría casi decirse que padecen este y todo poeta $-\mathrm{y}$ es cierto que existe la agnosia visual del objeto en reposo-.

${ }^{7}$ Bajo el título "La Beauté", ["La Belleza"], dicen así los primeros versos del poema: "Je suis belle, ô mortels ! comme un rêve de pierre, / Et mon sein, où chacun s'est meurtri tour à tour,/ Est fait pour inspirer au poète un amour / Éternel et muet ainsi que la matière." ["Soy bella, oh mortales, como un sueño de piedra, / Y mi seno, donde todos han sido heridos / Inspira al poeta un amor / Eterno y mudo como la materia."] 
La Beauté estatuaria e inmóvil del poema epónimo decía de sí misma: "je trône dans l'azur comme un sphinx incompris" [“domino en el azur como incomprendida esfinge"]; el poeta, sin embargo, ve a la passante como un animal alado y móvil —aunque igualmente inquietante: un águila agile et noble (y en agile apenas se disimula la metátesis que esconde el nombre del noble pájaro: aigle) ${ }^{8}$ - . La passante levanta y hace batir con la mano unas faldas que son como alas; avanza negra y majestueuse - depredadora, real, elegante y rápida son los adjetivos que convienen a un águila-; conmociona al poeta con su ojo de violenta pupila y potencia de visión mucho mayor que la humana (pues ve y sabe del poeta lo que este esconde: "Ô toi que j'eusse aimée, ô toi qui le savais!"). El poeta se caracteriza a sí mismo como ciego que solo ve cuando la luz se encuentra asociada a movimiento - “Un éclair... puis la nuit! - Fugitive Beauté”mientras, en contraste, atribuye a la passante esa potente visión que permite representarla metonímicamente como ojo, y que, además, incluye el poder de hacerle renacer: "Fugitive Beauté / Dont le regard m'a fait soudainement renaître".

Así pues, las estrategias perceptivo-cognitivas del poeta flâneur frente a la esterilizante Beauté estatuaria ${ }^{9}$ son: la desintegración de la unidad de la experiencia visual, la visualización del objeto sólo en situación dinámica y — estrategia que a continuación se analizará— la fragmentación de la imagen como consecuencia del rechazo de la "presencia amodal". Huelga decir que tales estrategias de extrañamiento no son del poeta (yo

\footnotetext{
${ }^{8}$ Este caso de doble imagen mental — figura de la passante y águila- podría ser objeto de análisis desde la perspectiva del siguiente apartado del presente texto — con título "Interpretación y metáfora"-. Aquí la imagen mental realista está basada sobre el contenido de los signos que transmiten los diferentes rasgos constitutivos de la imagen visual. Y, por su parte, la imagen mental metafórica está basada sobre: a) una analogía construida sobre la selección de los mencionados rasgos de la imagen visual; b) un juego anagramático (metátesis) sobre el significante de un signo.

${ }^{9}$ Reza así el poema "La Beauté”, [“La Belleza”]: "Les poètes, devant mes grandes attitudes, / Que j'ai l'air d'emprunter aux plus fiers monuments, / Consumeront leurs jours en d'austères études" ["Los poetas, ante mis grandiosas actitudes / que parecen propias de los grandes monumentos, / consumirán sus días en austeros estudios"].
} 
lírico o personaje) más que en la medida en que puede atribuírselas la lectura poética. Pues es esta propiamente la que construye una imagen mental no competitiva en terreno de mímesis; muy al contrario: la imagen mental resultante en la lectura poética se concibe como un extrañamiento de la imagen visual.

A tenor de las mencionadas estrategias, no cabe esperar que, en el poema, la imagen mental dé en permanente y estable imagen unitaria representativa de la mujer, ni tampoco en su metáfora implícita de águila. Es cierto que en toda descripción — como afirma Mendelsund (2015: 164) los datos que leemos no son acumulativos, no vemos todos los detalles componiéndose en una imagen unitaria, como sí ocurre en la visión. Los datos van quedando en segundo plano, por mucho que la sintaxis quiera ligarlos y conservar su presencia en la imagen mental en construcción. La poesía parece incluso renunciar a intentarlo, desfigurando a menudo la coherencia sintáctica, privilegiando el esbozo o el detalle descriptivo único y aislado — esbozo y detalle que no integran partes en un todo y por ello no apuntan hacia la mimesis realista global- Las dificultades de integración de los elementos descriptivos en imagen global suelen tener en la narración un rendimiento de dosificación de información - por ejemplo, en la creación de suspense o en la particular construcción de la entidad narradora-, pero en poesía el lector no espera tales rendimientos y tiende a considerar la falta de integración como un procedimiento genuinamente poético.

Sucede en el poema que la descripción de la passante - tras reconocerla breve y unitariamente como mujer - vuelve a mostrarla fragmentaria y diseminada, esta vez no por mor de la selección de los atributos de la visión sino por los del propio objeto de visión. La passante es pues vista como cuerpo despiezado — mano, pierna, ojo-, ajustándose de ese modo a un modo mundano y manipulable de Belleza-mercancía - el de la prostituta baudelairiana-, propio de una sociedad que ensaya su mercantilización y que fetichiza el cuerpo femenino ${ }^{10}$. Una mano que

10، ... la prostitución parece contener al mismo tiempo la posibilidad de mantenerse en 
sujeta la falda, una pierna que avanza, un ojo que mira son los fragmentos de cuerpo que se distinguen de la enlutada figura: como si el negro ocultara el cuerpo y este ya no pudiera ser reconstruido y reconocido por la vista. Esta imagen mental de la lectura poética tiene algo de cuadro vanguardista $\mathrm{y}$, desde el punto de vista de la percepción cognitiva parece no plegarse a los hábitos de la visión en la llamada "presencia amodal" (Kanizsa, 1986), donde se percibe un objeto íntegramente aunque la visión del mismo no sea más que parcial, pues los objetos del mundo suelen estar visualmente interceptados y fragmentariamente ocultos por otros en las escenas a las que asistimos, y no hay "modo" perceptivo que pueda respaldar al cien por cien el reconocimiento íntegro que finalmente tenemos de ellos.

La lectura poética — y más generalmente literaria — desautomatiza esta corrección e implementación perceptiva de la "presencia amodal" para producir extrañamiento en la imagen mental del lector. Aún más que en la narración, la descripción sin vocación realista de la poesía presenta un carácter lacunario que casa bien con el que requeriría de la "presencia amodal". Y si es lícito pensar que los procesos de rellenado del espacio perceptible y de construcción de coherencia del mismo sugieren analogía con los procesos presentes en el círculo hermenéutico — es cierto que la neurociencia corrobora aspectos de la lectura y la interpretación descritos con anterioridad por la hermenéutica-, parece también posible presumir que, en lo que a la poesía se refiere, tanto la "presencia amodal" como la interpretación de la escena quedan suspendidas a mitad de camino: no se construye ninguna conclusión de los procesos sino que se mantienen en una apertura que permite ambigüedades y dobles posibilidades de interpretación y de imagen mental.

un espacio vital en el cual los objetos de nuestro uso más próximo se han convertido crecientemente en verdaderos artículos de masas. En la prostitución de las grandes ciudades hasta la mujer misma se convierte en artículo de masas." (Benjamin, 2014: 221-222). 


\section{INTERPRETACIÓN Y METÁFORA}

La literatura es —entre otras cosas - un registro de la estabilidad e inestabilidad constantes de los procesos cognitivos. A diferencia de la narrativa, el lenguaje poético —además de someterlos a experiencia y a experimento en la dimensión perceptible de su soporte lingüísticoprescinde de la dimensión ficcional y se concentra en su observación asumida por un sujeto en la lectura poética. El sujeto lector de poesía se ofrece a sí mismo como encarnación de esos procesos cognitivos in nuce en el texto, y provee las emociones y la memoria corporal necesarias para convertirlos en realización efectiva. Así pues, la lectura poética se sirve de los procesos del cerebro del lector y de ellos depende. No hay nadie que le releve en la tarea y se ve obligado a asumir y convertir en reales todos los procesos que la narrativa reparte entre lector, narrador y personaje.

Cognitivamente, la metáfora refleja la que es constante actividad del cerebro: comparar lo percibido (física o imaginariamente) con patrones (valores constantes)y localizar cambios significativos: "la metáfora funciona al invocar y luego frustrar la búsqueda de constancia (...) [haciendo] posible una nueva configuración de parte y todo. La metáfora juega con la necesidad contradictoria del cerebro de constancia y flexibilidad" (Armstrong, 2013: 88). El estado normal del cerebro es precisamente el de un equilibrio inestable entre lo que busca y lo que encuentra, entre el reconocimiento de un patrón, la localización de disonancias respecto de este y la fabricación de otro patrón mediante operaciones que se procesan en diferentes lugares cerebrales y a diferentes velocidades y solo se integran de manera incompleta. "Esta integración incompleta hace posible que el cerebro entretenga interpretaciones conflictivas de las entradas que recibe." (Armstrong, 2013: 67)

El cerebro no puede hacer dos interpretaciones simultáneas - no puede contener dos imágenes mentales simultáneas - pero sí sucesivas e interrelacionadas. La metáfora es la expresión de un tipo de interrelación y describe un trayecto inacabado entre imágenes mentales en el que se 
traslucen procesos no conscientes (Gamoneda, 2018: 64). A este respecto, Jackendoff sostiene en su "Teoría de la Conciencia de Nivel Intermedio", que ni las señales percibidas ni los procesos de cognición superior se sitúan en la conciencia. Solo son conscientes las informaciones elegidas entre las pertinentes y procesadas de manera intermedia (Jackendoff, 1998: 221226). Pero se diría que en la lectura poética se traslucen esos procesos de selección de información previos al resultado que usualmente entra en la conciencia. El momento poético es ese en el que lo perceptivo ensaya significaciones resultando que hay disonancia con los patrones conocidos. Y la metáfora es el reconocimiento de un patrón aproximado que conserva la disonancia y por ello produce extrañamiento cognitivo: de este modo inflexiona hacia y "reflexiona" sobre su propio proceso cognitivo (y por ello quizá una parte importante de la poesía moderna ha terminado convirtiendo al modo cognitivo poético en su gran tema, al tiempo que ha desterrado las formas convencionalmente metafóricas: no es que no le interese la metáfora resultante, es que lo que le interesa es su proceso como desencadenante de lo poético).

"El conflicto de interpretaciones en las humanidades, sin la disponibilidad de apelación a un juez neutral, es una manifestación social y cultural de la competencia entre patrones alternativos por los cuales el cerebro negocia su forma cognitiva a través del mundo" (Armstrong, 2013: 74). La lectura hermenéutica es una competencia de capacidades metafóricas, de reconocimiento de patrones, de extrapolación de partes. Y el interés mayor se encuentra en la posibilidad que tiene el cerebro en realizar la operación interpretativa con resultados divergentes y casi simultáneos. Una capacidad cognitivamente muy explorada en el ámbito de las llamadas “imágenes multiestables” (pato-conejo, ánfora-dos caras), que perceptivamente pueden ser interpretadas de uno y otro modo, dependiendo del amorçage que se les procure. Reconocer ambas opciones y cambiar con rapidez de una a otra produce a nuestro cerebro cierta sorpresa - una versión rudimentaria y algo mecánica del extrañamiento metafórico- - y la evidencia de que nuestra percepción implica selección y 
combinación: hay analogía entre leer poéticamente y reformular el mundo.

Metáfora y lectura poética son modos cognitivos que eligen la inestabilidad/multiestabilidad cognitiva (y de sus imágenes mentales): que eligen el pato y el conejo — podría decirse — : que consiguen pasar de uno a otro con toda la velocidad que permiten los procesos de integración requeridos por la conformación de las imágenes mentales. Una imagen multiestable elige también el lector del poema de Baudelaire en el doble despliegue interpretativo del segundo cuarteto: "Moi, je buvais, crispé comme un extravagant, / Dans son oeil, ciel livide où germe l'ouragan, / La douceur qui fascine et le plaisir qui tue." Los versos contienen una sintaxis que separa el sujeto y el verbo de su complemento, de donde resulta que, en el primer verso, la imagen mental es la del poeta bebiendo en actitud bohemia - como resultado de un amorçage contextual que viene dado por la biografía de Baudelaire y por el propio poema (los pasos de la mujer se acercan y después se alejan, luego el flâneur está quieto, tal vez sentado en una terraza de café)- - Pero cuando el lector llega a los complementos del verbo - "Dans son oeil, ciel livide où germe l'ouragan, / La douceur qui fascine et le plaisir qui tue." - se deshace la imagen directa y realista, y "beber" se convierte en metáfora del surgimiento de la pasión a través de la mirada: bebe en un ojo huracanadamente pasional, bebe los vientos por ese ojo.

Pero no por ello pierde el lector la interpretación realista: el poeta sigue en su actitud bebedora y bohemia - "crispado como un extravagante"-, y lo que bebe - "La dulzura que fascina y el placer que mata"es un alcohol cuya precisa naturaleza se aclara mediante la comprensión del ojo de la passante como su metáfora: metáfora de la absenta, ese alcohol de moda entre bohemios de la época llamado "el hada verde", que al mezclarse con agua para ser consumido se enturbia y blanquea, y que produce una ebriedad reputada entonces como peligrosa. Así que la escena literal y realista del bebedor se funda sobre la metáfora no explícita (ojo/ absenta), mientras que la escena imaginaria — la de la efusión amorosa que el poeta desea - se funda sobre la lectura literal de una comparación ex- 
plícita del ojo con un cielo nuboso y que amenaza tempestad. Pato y conejo: las dos escenas se superponen, son comprendidas (interpretadas por el lector) al mismo tiempo —o casi—: coexisten; y además se construyen la una a la otra de manera quiasmática, funcionando para una en el plano realista lo que en la otra funciona de manera metafórica.

Este modelo de construcción quiasmática con efectos de multiplicidad interpretativa simultánea es frecuente en el poema, donde pueden señalarse ejemplos varios: "Agile et noble avec sa jambe de statue" responde a las dos concepciones encontradas de la Beauté —al igual que "Ciel livide où germe l'ouragan", donde el ojo no solo es el de la Belleza dinámica y apasionada sino también el ojo vacío ("[li]vide") de la Belleza estatuaria-; "Car j'ignore où tu fuis, tu ne sais où je vais" representa una trayectoria física pero también la imposibilidad poética de alcanzar la Beauté; "La douceur qui fascine et le plaisir qui tue" puede referirse tanto a los oximorónicos efectos del amor como a los de la absenta. El quiasmo - ya se ha dicho - es la forma diagramática del fugaz encuentro con la passante. Y es quizá también la del punto donde podrían darse simultáneamente las imágenes mentales de la metáfora y su referente, la forma diagramática de la imagen multiestable, el logograma mental de la metáfora en el momento en que esta aún guarda sus dos polos en relación dinámica y constructiva.

\section{FINAL EN PRECARIO}

Hay una precariedad enriquecedora en los procesos de la lectura poética que remite a nuestros humanos recursos y que reconocemos también en niveles diversos de nuestra naturaleza. La noción de "bricolaje", activa en el pensamiento salvaje de Lévi-Strauss, en las teorías sobre evolución biológica humana (François Jacob) y en muchas comprensiones de la neurobiología del cerebro y de su reciclaje neuronal, conviene también a estos procesos de lectura poética en los que el lector parece abrir la caja de los útiles cognitivos más básicos y arreglarse con ella en lugar de acudir a 
sofisticada ingeniería.

En la "historia natural" de la evolución del cerebro lector que cada uno de nosotros puede reconocer en sí mismo, Wolf señala cinco fases, que dibujan cinco tipos de lector: el incipiente, el novel, el descifrador, el de comprensión fluida y el experto. Los dos últimos tipos de lector son capaces de automatizar la lectura y de trascender la información dada, y con ello conseguir habilitar tiempo para pensar durante la lectura misma (2008: 159). Este gran logro es muy importante para toda lectura reflexiva y crítica, pero no verdaderamente para la lectura poética. El cerebro de un lector de poesía adulto es forzosamente fluido y experto - también existe el cerebro lector de poesía en niños: reconocimiento de ritmos, potencia de la lectura logográfica (Wolf, 117), implicación de ambos hemisferios (Wolf, 151-152) - pero esa fluidez y esa experticia le sirven también para habilitar un modo lector que revitaliza aspectos subsumidos en la automatización de la lectura: la desautomatización escenifica reencuentros entre el sonido y su significado, y con ello intensifica experiencias vivenciales y corporeizadas de vinculación de lenguaje y mundo. Todos somos algo niños cuando leemos poesía, todos recuperamos la capacidad de sorpresa cognitiva en la experiencia lectora poética, un extrañamiento que es el de la remisión a nuestras formas básicas de vincular experiencia sensomotora y lenguaje, al origen de toda capacidad metafórica. La lectura poética sacrifica intelección —afirmaba el Monsieur Teste de Valéry-; es decir, quizá no permite añadir reflexión entre líneas, pero redescubre y potencia los procesos por los que el pensamiento modelado en lenguaje reivindica su naturaleza creativa y su enraizamiento en el cuerpo: la lectura poética es trasunto de la escena originaria de lo humano - esa ucrónica escena de radical inestabilidad y extrañamiento cognitivo en la que no fuimos y fuimos humanos-. 


\section{REFERENCIAS BIBLIOGRÁFICAS}

ARMSTRONG, P. B. (2013). How literature plays with the brain. The neuroscience of reading and art. Baltimore: Johns Hopkins University Press.

BAUDELAIRE, Ch. (2005). Les fleurs du mal. París: Gallimard.

BENJAMIN, W. (2014). "Parque central". En Baudelaire, J. M. Cuesta Abad (ed.), 207-247. Madrid: Abada.

CHANGEUX, J.-P. (2008). Du vrai, du beau, du bien. Une nouvelle approche neuronale. París: Odile Jacob.

DEHAENE, S. (2007). Les neurones de la lecture. París: Odile Jacob.

DEHAENE, S. (dir.) (2011). Apprendre à lire: des sciences cognitives à la salle de classe. París: Odile Jacob.

GAMONEDA, A. (2014). "Sentidos seducidos". Signa. Revista de la Asociación de Semiótica 23, 429-441.

(2016). "La descripción especular. Lectura neurocognitiva de $L a$ Jalousie de Robbe- Grillet”. Tropelías. Revista de la Literatura y Literatura comparada 25, 1-16.

(2018). "Eureka y epifanía. Diluciones cognitivas y poéticas". En Idea súbita. Ensayos sobre epifanía creativa, A. Gamoneda y F. González (eds.), 45-74. Madrid: Abada.

JACKENDOFF, R. (1998). La conciencia y la mente computacional. Madrid: Visor.

JOHNSON, M. (1991). El cuerpo en la mente. Madrid: Debate.

KANIZSA, G. (1986). Gramática de la visión: percepción y pensamiento. Barcelona: Paidós.

LAKOFF, G. \& JOHNSON, M. (1986). Metáforas de la vida cotidiana. Madrid: Cátedra.

MARTINDALE, C. (1990). The Clockwork Muse: The Predictability of Artistic Change. Nueva York: Basic Books.

MENDELSUND, P. (2015). Qué vemos cuando leemos. Barcelona: Seix Barral-Planeta. 
MESCHONNIC, H. (1970). Pour la poétique. París: Gallimard.

OLIVIER, G. (2012). La cognition gestuelle. De l'écho à l'ego. Grenoble: Presses Universitaires de Grenoble.

OUELLET, P. (2000). Poétique du regard. Littérature, perception, identité. Limoges: Presses Universitaires de Limoges.

PERRONE-BERTOLOTTI, M.; KUJALA, J.; VIDAL J. R.; HAMAME, C. M.; OSSANDON, T.; BERTRAND, O.; MINOTTI, L.; KAHANE, Ph.; JERBI, K. \& LACHAUX, J. Ph. (2012). "How Silent Is Silent Reading? Intracerebral Evidence for Top-Down Activation of Temporal Voice Areas during Reading". Journal of Neuroscience 32.49, 17554-17562. http://www.jneurosci.org/ content/32/49/17554 [01/05/2018].

QUIGNARD, P. (2016a). Pequeños tratados I. Miguel Morey (trad.). Madrid: Sexto Piso.

(2016b). Pequeños tratados II. Miguel Morey (trad.). Madrid: Sexto Piso.

RAMACHANDRAN, V. S. (2012). Lo que el cerebro nos dice. Barcelona: Paidós.

RIZZOLATTI, G. \& SINIGAGLIA, C. (2008). Les neurones miroirs. París: Odile Jacob.

SHKLOVSKI, V. (1991). "El arte como artificio". En Teoría de la literatura de los formalistas rusos, T. Todorov (ed.), 55-70. México: Siglo XXI.

TURNER, M. \& FAUCONNIER, G. (2002). The Way We Think. Conceptual Blending and the Mind's Hidden Complexities. Nueva York: Basic Books.

WOLF, M. (2008). Cómo aprendemos a leer. Historia y ciencia del cerebro y la lectura. Barcelona: Ediciones B.

ZEKI, S. (2005). Visión interior. Una investigación sobre el arte y el cerebro. Madrid: A. Machado Libros.

Recibido el 6 de agosto de 2018.

Aceptado el 6 de septiembre de 2018. 
